\title{
EL RÉGIMEN DE LA VERDAD Y LA RAZÓN PRAGMÁTICA*
}

El hombre que empieza a hablar en Grecia con pạlabras de razón es un hombre nuevo; pero también es hombre nuevo el que las escucha. Las innovaciones que trae la filosofía no son nada más las del conocimiento, sino las de la existencia, y éstas no están representadas sólo por filósofos. Pero ¿cómo pudo afectar a todos la especial forma de vida de unos pocos? Los afectó porque la filosofía no era una especialidad. Era universal en el sentido de omnímodamente comunicativa. Las proposiciones de la ciencia son "universales y necesarias", como establece Aristóteles. Desde entonces, al pensar en esta universalidad de la forma lógica, y en esta necesidad respecto del contenido, olvidamos la universalidad del alcance humano que tuvo la filosofía en su inicio.

La filosofía descubre la verdad. Su fuerza de penetración original proviene de ahí: no de las verdades que propone el filósofo, sino del hecho de la verdad. Cada hombre ha de atenerse desde entonces a este hecho: hay verdad. Pero la verdad es palabra de razón, palabra que interroga por el ser y que da razón del ser. Antes de la verdad, hay la palabra sincera de la veracidad, la cual expresa actitudes o intenciones subjetivas. La veracidad cualifica una disposición del que habla frente a su interlocutor. La relación pura con el ser no se cualifica subjetivamente. Por eso se llama pura. La veracidad es contingente. Puede ser base de comunicación dialógica, pero no contiene la necesidad inherente a una base universal de comunidad. Su contrario es la mendacidad. La verdad de razón no tiene contrario; pues el error, que parecería su contrario, lleva la misma intención: implica la misma posición de base en la racionalidad común.

Esta posición es lo distintivo. Antes de la filosofía, la base común en que se sitúa el hombre para hacer frente a la realidad es la creencia, la tradición aceptada sin escrutinio, sin conciencia siquiera de su carácter básico. El mito trata de explicar, pero no da razón. En el mito se cree o no se cree; es asunto de creencia, y no de evidencia: es un testimonio que representa mejor la comunidad que lo forja que la realidad explicada. Sin duda, la convivencia establecida en esta base habría de recurrir a todas las pequeñas verdades de hecho que permiten la identificación de los entes. No es posible entenderse sin conferir a cada cosa su "esto" definido. Estas verdades no daban entonces, ni dan hoy, sustento cabal. Son base vital, pero de una vida más primaria, y para un hombre que no era cabal en su ser. Algo le faltaba,

- Notas para una obra en preparación que se tịtulará La reforma en la filosofia. 
y era la posesión de este ser. Conformaba su expresión y su comportamiento ateniéndose a lo dicho y a lo hecho, a la tradición que marca el cauce de lo que se hace y se dice, con una orientación y una responsabilidad difusas.

$Y$ cuando el pensamiento se individualiza, la $\delta o ́ \xi \alpha$ personal inicia la crisis de esa responsabilidad básica del habla común, pero no la remplaza. La opinión no es base: ésta es una de las advertencias primeras de la filosofía, patente modélicamente en Heráclito y Parménides. A la $\delta o ́ \xi \alpha$ anterior a la filosofía hemos de darle el valor de un síntoma: es una presunción de la verdad, un titubeo hacia algo que sea como una manera original y autóctona de ver las cosas. Lo que le falta es la comunidad. La verdad racional restaura la comunidad que tenía la creencia, y supera la relatividad de la $\delta$ ó́ $\alpha$. Es el remate de un largo proceso de individuación. Para que la individualidad no fuera disolvente, había de crearse una nueva forma de responsabilidad del verbo. La razón es responsable. Dar razón significa aportar justificantes admisibles en común. Sólo así podía remplazarse la base de comunidad de la palabra heredada con la base de comunidad de la palabra libre.

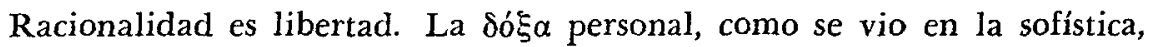
ha representado siempre en filosofía un desdén por la verdad responsable; en la vida, representa un peligro para la libertad que procura en la base la razón común. La opinión no es libre. Cuando cree liberarse de disciplinas, revela la sumisión del pensamiento a unos intereses limitados por la subjetividad. La estrechez de su base tiende a ampliarse pragmáticamente, por vía de proselitismo o de imposición; lo cual confirma que no es base común por naturaleza. El logos de verdad es comunitario porque es objetivo. Ahora la responsabilidad del verbo se cifra en la objetividad. El apoyo vital se

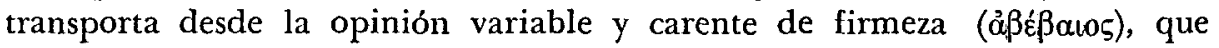
sólo es base para un sujeto, o para quienes lo acompañen, hasta la realidad del objeto mismo, que es común, y base invariable. Pero la objetividad altera la subjetividad. Adoptar como base la realidad presentada racionalmente, significa convertirla en el medio más efectivo de comunicación y entendimiento. Este entendimiento cambia la forma de ser de los comunicantes.

Por esto, si preguntamos cómo consigue reformar la comunidad, veremos que el filósofo no emplea ningún artificio didáctico. Al principio, la filosofía no se enseña. Enseñar es abrir el propio recinto, y todavía no hay recinto: la filosofía original es pública, no es reclusa. Sus palabras atraen la atención porque son comunes, a la vez que innovadoras. Invitan al entendimiento simplemente porque están ahí: no pueden ser desoídas.

Para imaginar el efecto que produciría en los griegos el verbo nuevo de la filosofía, es preciso de algún modo rehacer la experiencia de la primera aparición de la verdad en la vida, y recuperar por ahi el sentido original de 
la razón, que hoy se encuentra soterrado bajo capas sucesivas de especializaciones. Antes de poder explicarnos con detalle el funcionamiento de la razón, en unas teorías del conocimiento muy elaboradas, como las de Platón y Aristóteles, la filosofía presocrática realza la comunidad de la razón, y

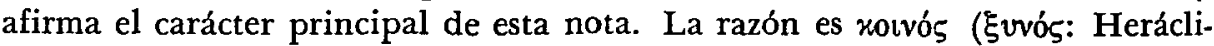
to, B2). Es común en tanto que expresión estricta, y por esto accesible a todos. Este es el logos como verbo: forma y contenido de una comunicación inteligible. Es común en tanto que pensamiento: logos como razỏn objetiva, que suprime las barreras del punto de vista y de la opinión singular. Es común en tanto que la realidad que este pensamiento y esta palabra ofrecen, en un acto de comunicación que es un literal ofrecimiento o presentación (ảsópavoเs), es una realidad común: la misma para todos (Heráclito, B 30). Finalmente, es común porque es base o fundamento universal: la razón instaura en la vida el régimen de la verdad.

En el origen no hay profanos. Todo lo que dice la filosofía concierne a todo el mundo. Nunca en la historia se ha vuelto a repetir, ni podría repetirse en igual grado, esa atención que recayó sobre las primeras palabras de la filosofía. Atención que no se explica sólo por la voraz curiosidad del griego, ni por su vocación verbal. Si la lengua no se ha diversificado en múltiples lenguajes de especialidad estanca, todo lo que se dice tiene que ser oído y entendido por todos. Más todavía, cuando esta misma palabra se propone dar razón, y la ofrece de algo que es común, no de algo recóndito que pueda desecharse, si el interés personal no se siente atraído por lo misterioso o peculiar. Al contrario, el verbo nuevo arroja una luz que es más insospechada porque recae sobre lo ya conocido, y esto aumenta la fascinación. No devela o revela algo oculto. Habla del ser, y el ser está a la vista. Lo oculto son las razones, que la razón ha de investigar. Las cosas son las mismas, pero parecen distintas, si logramos considerarlas sólo en tanto que son: puramente en su ser, y no habitualmente como servibles. Comunidad y pureza son las dos notas primarias de la razón.

Hay extrañeza en la medida en que hay sorpresa. Por esto Platón reconoce que el filosofar procede del $\theta \alpha \tilde{u} \mu \alpha$, que es la sorpresa. Y no sólo procede de él, sino que lo fomenta. El filósofo es ingenuo, primero por dejarse sorprender, y luego por divulgar su sorpresa. El sofista ya es taimado: sorprende a los demás, haciendo del verbo un espectáculo, pero quedando él mismo a salvo de cualquier sorpresa. Lo sabe todo, nunca duda. Pero no ha llegado el día en que saber lo que el otro no sabe sirva para tenerlo dominado. Para el filósofo primitivo, la comunicación del saber es un contagio de la sorpresa. No quiere ser él quien sorprenda. La sorpresa de la verdad es anterior a la que produce el hallazgo teórico. Lo que sorprende al griego es que la nueva razón sirva para comprobar que las cosas tienen sus razones. "Tener razón" ya no es una ventaja personal; es hablar de la razón que tienen las cosas, 
o sea decir la verdad. En esto, que no había sucedido antes, consiste la revelación de la verdad. Ver las cosas racionalmente, verlas como racionales ellas mismas, no cambia las cosas, pero cambia a quien aprende esta manera de ver y de hablar.

Insistamos en la cuestión: ¿por qué fueron todos los afectados? Se comprendería que esta peculiar relación con el ser, que es la relación de verdad, influyera hondamente en el sujeto de la relación; porque ésta es desusada, no es la natural y cotidiana. Cotidianamente, no vemos al ser en su ser; es más natural verlo en su valer, dándole un precio. Pero otra cosa es escuchar las palabras del filósofo; aunque hable del ser inapreciable, no parece que esto haya de causar sin más ningún cambio en el oyente, menos aún en los nexos de comunidad. Los cambios se producen, sin embargo. La palabra. siempre produce efectos. Los produce más hondos, si es una palabra nueva. Entonces alcanza a la propia forma del ser humano. La mente receptora no se limita a registrar la novedad. Menos aún cuando la palabra nueva no trae sólo un mensaje, sino un nuevo régimen. La verdad es un régimen.

Este es el punto principal, y hemos de fijarlo para comprender nuestra propia situación, pues ésta se caracteriza por la crisis de aquel régimen de la verdad.

La verdad de este régimen no es una verdad, esta o aquella, ni un tesoro de muchas verdades reunidas. No es un dato positivo, ni se encuentra en la frase de un solo filósofo, o de unos cuantos. No es un consenso deliberado, ni es la simple congruencia abstracta entre dos pensamientos. Es, inclusive, algo más que una teoria verdadera, adoptada por una mayoria. La base no está, pues, en las verdades conocidas, en un saber logrado y acaudalado. El régimen de la verdad se encuentra sólo en la disposición a basar la vida en la verdad, y no en otra cosa.

El gran hallazgo consistió en descubrir que la vida humana está basada: hay que basarse o fortificarse en lo común (Heráclito, B 114). Este hallazgo coincidió con el de la razón, que es buscadora de verdades. De suerte que los griegos, y quienes hemos venido después, no hablamos de sospechar siquiera que, dada la necesidad de una base, pudiera proponerse otra que no fuese la verdad. ¿Cuál podía ser? No podía ser nada contrario a la verdad: lo que se opone a la verdad la presupone. Tendria que ser algo indiferente. Pero ces posible imaginar algo que sea indiferente a la verdad, algo que escape a la universalidad de su régimen?

La razón, la base y la verdad quedaron asociadas; vinieron de este modo a formar una unidad vital que ha regulado perdurablemente la existencia humana, y que ha sido tanto más indestructible, cuanto que no se afiliaba a ninguna doctrina particular, por verdadera que ésta pudiera ser. La unidad del régimen no era asunto de doctrina, y esto explica que el régimen 
mismo fuese universal y efectivo: que se formasen en él incluso aquellos que no tienen acceso a las verdades de teoría. También explica que el escéptico sea un extravagante, precisamente en una comunidad donde predomina la duda; porque sin dudas no se accede a las verdades, y antes de la verdad no hay escépticos. La duda es el afán de verdad; el escéptico es un dogmático desengañado.

La instauración del régimen de la verdad no hubiera sido posible, si là relación racional con el ser no fuese, a pesar de su pureza, o tal vez por esto mismo, una relación dialógica. Lo que debemos fijar aquí, sin necesidad de entrar en más hondos análisis, es que la verdad, lo que hoy llamamos verdad científica, no sólo forma una base para los filósofos, los especialmente vocados. Tenía que ser una base común, porque el logos verdadero es un logos común. No lo es por difusión, ni porque todos los hombres se hayan definido como constitutivamente dotados de facultad racional. Antes de la filosofía, no podían definirse de este modo. Es ella, la razón misma, la que es constitutivamente comunitaria o comunicante.

Supongamos que el conocimiento científico se redujese sólo a dos términos, el conocedor y lo conocido. La relación no afectaría manifiestamente más que al protagonista solitario. Los demás sólo podrían ser testigos mediatos de su experiencia, cuando él la manifestase. El acto de comunicación sería entonces eventual y derivado. Pero no lo es. La expresión es originaria o gestora de la objetivación. No hay evidencia que no sea común; y en tanto que común, vinculatoria. El ser conocido es ser comunicado. Se piensa con palabras, y sólo con palabras. El acto primero de la ciencia consiste en dar nombres. Esta función verbal no caduca después de los inicios. La operación nominativa tiene que repetirse en cada acto original de pensamiento. Si disminuyen su frecuencia y su resonancia, es porque existe ya un vocabulario de nombres reconocidos y acreditados como vías de comunicación. Las cosas tienen su título propio; quiere decirse que los entes están definidos, identificados en su ser de verdad, y no sólo en su presencia. La esencia dialógica del logos queda entonces encubierta por la abundancia del lenguaje especializado.

No fue así en el principio. ¿Por qué se llamó logos a la nueva razón? Pudo llamarse voũs. Pero el concepto de pensamiento racional no incluye declaradamente la comunicación. En cambio, el logos es verbo, no sólo raciocinio; es una manera de hablar, y no sólo de ver, de meditar o de asociar pensamientos. Por esto la filosofía, aunque sea reflexiva, no es una vocación silenciosa, como puede serlo la contemplación místíca. Ella da razón; no por compromiso profesional, sino por esencia. La relación racional con el ser es una relación verbal, es una forma nueva de elocuencia. Las razones son palabras. Las palabras de razón presentan o representan las cosas; por esto no se dirigen a ellas, sino a los hombres. 
Pero esa relación verbal no se restringe a los interlocutores filosóficos, ni siquiera al monólogo de éstos frente a los callados oyentes. Los oyentes son partícipes. Aunque no se sientan atraídos por alguna doctrina de los filósofos, los oyentes comulgan en la revelación del ser por la verdad. Es la intención de comunidad del verbo lo que se difunde, y esto altera la relación de unos hombres con otros. Ahora hay que referirse al ser, saber lo que es verdad y basarse en ésta, para referirse al otro. La verdad es base común para que cada uno sepa, en cada caso, a qué atenerse. Las verdades que se invoquen podrán ser verdades de hecho o de teoría, principales o triviales. La mutación no la produce ninguna de ellas, de manera precisa. La mutación consiste en adoptar la palabra de verdad como forma de relación; la cual pueda invocarse cuando alguien no la adopta y "falta a la verdad".

Faltar a la verdad es querer salir de la base común, sin lograrlo. Y todo esto es posible porque la relación de verdad, siendo una relación verbal, es por ello esencialmente veri-ficable. Porque, desde luego, no toda palabra es en sí verificable, que quiere decir: lo abarca todo e incorpora a todos. Hay formas verbales que no proponen verdades. Éste es el reverso del gran hallazgo. La poesía, por ejemplo, no es verdadera ni falsa; es una palabra metaverdadera: está más allá de la verdad, aunque sea vecina del logos fílosófico; porque también constituye una relación pura con el ser.

La filosofía es introspectiva, y por esto son introspectivos todos los hom bres, desde que viven en régimen de verdad. Cuando preguntamos des esto verdad? miramos hacia afuera y hacia adentro a la vez. Lo mismo los profanos, que quienes hacen de la duda metódica una profesión, crean una forma de humanidad distinta; esto es, capaz de mirar al exterior de una manera distinta, habilitada por la capacidad de mirar al interior.

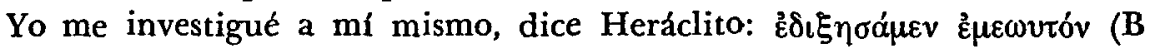
101). El verbo que emplea Heráclito para designar esa peculiar introspección (que no es el simple pensar en uno mismo, sino búsqueda de la mismi-

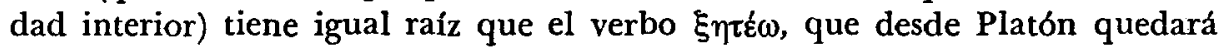
consagrado para representar la investigación científica. La ciencia no sólo investiga para dar razones de lo externo. Mejor aún: sólo puede dar razón de lo externo si está internamente conformada por la autoconciencia y la reflexión. La razón pura es pura por introspectiva. Parece que no podría concebirse una razón que no diese razón de sí misma. Por esto, toda ciencia ha de fundarse en una crítica de la razón, que es obra de ciencia primera. De hecho, nunca ha existido una razón sin razón, sino hasta ahora. Ahora ha aparecido; sin concepción, ciertamente, pero con fuerza de predominio.

La coyuntura de la razón en nuestros días es para ella, y por consiguiente para el hombre, un suceso singular, tan decisivo como su propio inicio. La razón, como órgano de la relación pura con el ser, sigue siendo la misma que 
formaron los griegos: la relación de verdad con el ser es inalterable, la relación de verdad entre los hombres es inalterable. ¿Qué ha sucedido entonces? Porque ninguna de las críticas de la razón que surgen en la historia de la filosofia, antes y después de Kant, ha alterado su constitución fundamental, ni se ha propuesto hacerlo. En todas esas variantes de teoria se encontraban, siquiera implícitos, los caracteres de la pureza y la comunidad. La verdad de razón ha podido ser fundamental o fundante en la vida humana, porque ella misma ha tenido, como fundamento constitucional, esa

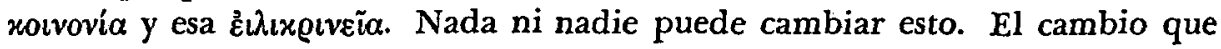
se produce empieza a distinguirse en una disminución de la frecuencia con que los hombres recurren a esta base, o se apoyan en ella para vivir. Es el. régimen de la verdad lo que ha entrado en crisis, y en una crisis que puede ser final.

El recurso a la verdad se inició históricamente en Grecia, pero se ha naturalizado en nuestro ser. La crisis de ahora trae una nueva revelación: es la posibilidad manifiesta que quedar desnaturalizados. Es preciso que la filosofía avive el recuerdo de aquellos orígenes del régimen de la verdad, pues de otro modo nadie estaría en condiciones de identificar el riesgo. Esta desnaturalización sólo podrá sobrevenir si aparece y se consolida una alternativa vital de la verdad: si la verdad es sustituida en la base por algo.que destrone su régimen. ¿Es esto posible?

Hemos de examinar qué pueda ser este "algo" nuevo, y si en efecto se está implantando un nuevo régimen. Hemos de recapacitar y de pasar balance de lo que fuimos. Nada puede importarnos más que un cambio en nuestro ser. Si este cambio es inevitable, podemos evitar por lo menos que se produzca enteramente a pesar nuestro, sin que tengamos conciencia del cambio mismo que estamos sufriendo. Los síntomas han de reconocerse por contraste, y éste no resalta si primero no comprobamos hasta qué punto transformó la condición humana el advenimiento de la filosofía, y qué firmeza tuvo el régimen de la verdad que ella instauró.

La crisis de la filosofía no es, pues, la crisis de una particular profesión intelectual. Hemos vivido todos creyendo implícitamente que la verdad no tiene alternativas. Cualquier alternativa sería inconcebible, esto es, algo que desborda lo extraño y lo absurdo, algo que literalmente no podría conceptuarse. Pues el error y todas las formas del engaño son conceptuables; contradicen a la verdad, pero pertenecen a su régimen. Nada contrario a la verdad puede constituirse en régimen. Más allá de la verdad essignificaría más allá de la razón? Imaginarlo siquiera es ya un escándalo para la razón; o algo peor todavía, algo que no cabe siquiera imaginar. En esta zona, como quiera que se delimitase, no aparece nada que pueda ser base común. La mística es base para el místico; no puede ser para todos, y más claramente aún, no puede ser para todo. La base no es sustento para algún orden espe- 
cial de vida, sino para todo orden de actividades. La bondad y la belleza no son alternativas de la verdad, cualesquiera que sean sus relaciones con el logos. Forman con la verdad precisamente una tri-logía, una unidad armónica sin disputa interna posible.

Examinando las condiciones de posibilidad de una tal alternativa, como si fuera a priori, se percibe de antemano que el nuevo régimen de base tiene que ser indiferente respecto de la verdad. Pero, segundo, que no puede ser indiferente respecto de la razón. Es necesario que conserve alguno de los caracteres que encontramos en la base tradicional, porque el nuevo nace del anterior, aunque lo remplaza. Mejor dicho, no podría remplazarlo si no tuviese un rasgo común que sirviera de viaducto para la transición. La continuidad la asegura la razón. La nueva base tenía 'que ser, y ha sido, una nueva forma de la razón.

Hemos de anotar inicialmente estos dos hechos: la razón que no sabe dar razón de sí misma ya no tiene nada que ver, por esto mismo, con la razón de las ciencias y de la filosofía. La distinción es radical, y tiene que prevalecer, pese a los parecidos externos y los equívocos que produzca una manera laxa de hablar. Lo que presenciamos ahora no es una apoteosis de la ciencia, sino su ocaso. Y segundo, la época que se inicia con esta razón ciega no es, en ningún sentido vital, una época de las luces. Iluminar es entender y entenderse. Las cosas se entienden con entendimiento racional. Los hombres pueden avenirse de varias maneras; pero sigue siendo cierto que entenderse, estrictamente, no pueden lograrlo sino con la razón. Sólo que ahora de lo que se trata no es de entender y entenderse. Las palabras decisivas ya no buscan esto; buscan una pronta decisión. Para ello deben despojarse de sus autoctonias, de sus buenos modales populares, de sus refinamientos y formalidades literarias y de su iluminación de entendimiento, para convertirse en una divisa de circulación internacional que abrevie los trámites de la acción.

Saber a qué atenerse ya no es un saber, ya no se logra con recurso a la verdad. Saber a qué atenerse es disponerse a seguir el camino más corto entre el propósito y su meta práctica. Lo cual, hay que advertirlo, no es cinismo personal, ni pragmatismo ideológico. El fin no justifica los medios: los impone. El dispositivo de los medios ha de ser tan calculado como el de los fines, con una exactitud que no deje lugar a dudas. Saber a qué atenerse es no poder dudar. El error, siempre posible, será un error de cálculo, cuantificable, y no el error cualitativo de la decisión humana. Saber a qué atenerse es reducir a una todas las opciones posibles, o sea suprimirlas. Lo decisivo no ha de tener alternativas: es como el movimiento físico. Sin base en la verdad, saber a qué atenerse es renunciar a ser libre.

La vida humana oscilaba entre la reflexión y el instinto. La primera es incierta y morosa; el segundo es certero, pero ciego. El cálculo de la 
nueva razón es como un nuevo instinto, certero y ciego, que hace lo necesario, pero sin justificarse. Trata con el ser, y muy eficazmente, pero no trata del ser. Por esto es anónima la nueva razón: no importa quién efectúe el cálculo; sólo importa su exactitud, pues de ella depende nada menos que la subsistencia humana, y la exactitud es más precisa cuanto más impersonal. Ahí se percibe muy bien el contraste: la verdad es común, pero, en su descubrimiento, el descubridor es personal e insustituible; mientras que, en la razón calculadora, hasta la máquina puede sustituir al calculador.

La seguridad que procura este anonimato aumenta por la uniformidad a que nos somete. Aunque calcular sea todavía usar de la razón, descubrimos ahora que es posible razonar sin entender, pensar sin expresarse. El 'cálculo era un auxiliar del saber, en las zonas de la realidad que admiten la cuantificación; ahora ha venido a ser, más que un medio de vida, que presupone otros medios distintos, la base misma de la vida. La existencia calculada sólo es viable a condición de que la razón calculadora sea inconsciente de sí misma, como lo es el instinto, y de que forme sistema, cosa que el instinto no logra. Los instintos son comunes, pero su actividad diversifica. La acción calculada ha de ser homogénea. Vista desde el nivel de la libertad racional, la razón que sabe contar, pero que no puede dar "cuenta y razón" de sí misma, podrá parecer una paradoja, pero no es una sinrazón. Justamente; la vida no había sido nunca tan "racionalizada". Hay que ir reduciendo al mínimo la animalidad, que el humanismo ha considerado siempre esencial a la humanidad: la reflexión no tiene juego sin la pasión y el instinto. Hay que suprimir lo inesperado: el nuevo régimen supera la animalidad, porque es sistema de razón, y suprime la personalidad de la razón reflexiva, porque es razón decisiva, forzosa y anónima.

El hombre nuevo que se va formando no quiere (en realidad, no puede) basar su vida en la verdad. No la desecha por disgusto irracional, ni la repudia por cinismo, lo cual sería todavía una elección. Abandona la verdad como base sencillamente porque no es eficaz para la subsistencia. La noción misma de existencia incluía la variedad real de las existencias; ahora esta variedad se ha de contraer a la uniformidad de la subsistencia. La universalidad de la nueva base se cifra en esto: todos somos iguales ante la subsistencia. Esto ocurre así por "razón de fuerza mayor". La verdad ya no es la base; pero la razón está en la base. Ésta ya no es la razón pura, sino la razón forzosa. La vida nueva ha asociado la razón con la fuerza.

Esta fuerza no es la que ejerce sobre el hombre la necesidad natural, ni la que ejerce el hombre sobre el hombre, y a la cual llamamos poder. El poder es objeto de ambición, y por esto objeto de disputa. Quiere decirse que el poder real es sólo un posible, que él mismo entraña la posibilidad de otro poder que lo desbanque. Su fuerza no es una razón forzosa. Y es que 
esta frase tan usual, "razón de fuerza mayor", no quiere decir lo que dice: con ella designamos justamente una sinrazón, algo que no admite ni sustitutos ni discusiones. Ahora es la propia razón la que no admite discusiones, porque posee ella misma una fuerza mayor. Esto no había ocurrido nunca. La razón era "mayor" porque era libre. El principio de razón pudo llamarse principium magnum porque no rige por el poder de nadie, y a la vez porque ningún régimen de poder llega a imponérsele.

La razón de fuerza mayor es una necesidad racionalizada. Su novedad estriba en que no da razones; de ahí su fuerza inapelable. Ninguna necesidad es responsable. A la nueva razón le basta con hacerse útil. La utilidad entra en la base por fuerza propia, no por iniciativa de unos interesados responsables. Pero este sitio, que es el de la verdad, no podía ocuparlo el interés utilitario si no se ajuntaba de algún modo con la razón. La utilidad ha existido siempre, pero no en la base; existe como algo primario y con fuerza mayor, sin una razón de fuerza mayor. La razón sola, o sea pura, no podia dar más que verdades. Para que rindiera utilidades había de transmutarse, habilitándose para regir como puro cálculo utilitario, excluyente de.la verdad. Las verdades sólo peligran cuando no tienen enemigo declarado.

Que la vida práctica tuviera que racionalizarse, además de inevitable, no era en sí pernicioso, sino más bien benéfico. No hay maleficio intrínseco en la tecnología moderna. Y esto es precisamente lo más grave: su completa inocencia, que es otra manera de decir su "fuerza mayor". El fenómeno de gravedad profunda no es la racionalización de la praxis, sino la pragmatización de la razón; porque esto sólo se logra por exclusión de la razón de verdad, que es pura por esencialmente desinteresada. Con esto se suprime la dualidad entre teoria y práctica: todo tiene que ser práctico.

No fallan unas ciertas verdades por su contenido, porque resulten inadecuadas a lo real. En este caso podrían ser sustituidas por otras, y se mantendría el régimen. Es el régimen el que está fallando, y falla por inoperante. La racionalidad desinteresada resulta ahora un factor de desorden. La libertad es un lastre. (Se entiende la libertad de ser.) Puede traer sorpresas, y la vida exige que todo esté previsto, pues la catástrofe total es inminente. La razón forzosa del interés común mantiene el orden en el nivel de la subsistencia. Esto impone renuncias: la razón forzosa no infringe, sino que suplanta, el régimen de la verdad.

La razón sigue siendo la base, pero la base se ha restringido. La razón sigue siendo "la mayor", porque se ha asociado a una fuerza que es "fuerza mayor". Por razón de esa fuerza, que impone la mecanización y cuantificación de la vida, resulta baldía la pretensión del mecánico. La pericia que posee le hace creer que él es protagonista del proceso. La figura que adopta, de rector del mundo moderno, es un resabio del antiguo régimen libre, en el cual todo predominio representaba el triunfo de una posibilidad entre 
otras, que eran las desechadas. Incorporarse a lo inevitable no es ningún triunfo. Pero ha de entenderse que esa fuerza mayor es todavía una fuerza histórica: es fuerza de razón. La razón es histórica incluso cuando cambia de mañera tan radical, que ya no da razón del ser, ni de sí misma, sino que actúa como razón forzosa.

La nueva razón es tema obligado de una nueva crítica de la razón. Es el porvenir de la razón humana el que debe investigarse, a la vista del proceso de erosión y desplazamiento que sufre la razón tradicional. La forma distinta de razón que está dominando progresivamente reclama su propia crítica. Pero esta incorporación de la razón nueva en el temario de la filosofía primera ha de alterar, por su sola presencia, la idea que nos habíamos formado de la razón: no habíamos previsto que al lado de la razón pura, reguladora del régimen de la verdad, pudiera aparecer otra distinta.

Dar razón de la nueva razón (la cual es incapaz de dar razón de sí misma) implica reafirmar, diríamos rescatar, la razón pura. Es de urgencia vital, y no sólo teórica, que no se confundan la una con la otra. Por ello, el horizonte de la crítica de la razón que ha de llevar a cabo la filosofia en nuestros días es más dilatado que el de ninguna otra crítica anterior. Ahora la razón pura debe recapacitar sobre su propio ser, tomando nota de que, a su lado, y pujando por eliminarla, actúa en la vida una nueva razón que no comprendemos bien, de la cual apenas somos conscientes, pues la confundimos con la antigua, pero de la que usamos sin saber cómo está configurada, cuál es su contextura, cuáles sean sus fines, y qué resultados vaya a causar su predominio en la comunidad humana. Ni siquiera tiene nombre.

Para entendernos, podriamos llamarla razón pragmática, antes de proceder a una caracterización que nos diga, sobre todo, lo que ella no es.

¿Qué se entiende por "dar razón"? ¿En qué sentido la razón que "se da" es pura?

La ratio reddenda no es una innovación de la filosofía moderna, ni en la concepción, ni siquiera en los términos. Estas palabras aparecen en la designación que hace Leibniz del principio supremo, como principium reddendae rationis sufficientis; pero no hacen sino traducir literalmente la fórmu-

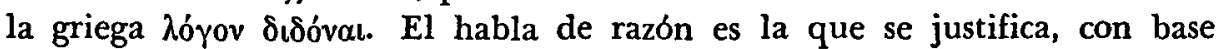
en la realidad, sin otra apelación posible, ni otra intención que no sea la verdad. En esto consiste su pureza. Como dice Platón: hablar de las cosas, tal como ellas son, en sí mismas. Es esencial a la razón de la filosofía, y de la ciencia en general, el dar y el darse. La razón pragmática no representa una evolución interna de la razón que produjo la episteme y que asentó el régimen de la verdad. Ésta no pretende dar razón, ni del ser, ni de sí misma. Lo que retiene es el saber positivo, que se obtiene con un fin de utilidad, o sea sin pureza. Lo que abandona es la intención vocacional de darse. 
En el darse quedaba cumplida y se renovaba la vocación del desinterés, que está en la esencia de la verdad. La razón pragmática podrá ser exacta, pero no es "verdadera": es "posesiva".

Universidad Nagional Autónoma de México

EdUARDo Nicol 